\title{
Author Index Vol. 50, 1997
}

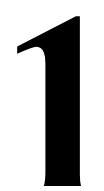

Brain, Behavior

\section{and Evolution}

KAKGER
Author Index Vol.50,1997

Liem, K.F. 167

Martinez-Garcia, F. 313

Martinez-Marcos, A. 313

Mathieson, W.B. 304

Menger, N. 261

Mogdans, J. 261

New,J.G. 244

Nishikawa, K.C. 50

Northcutt, R.G. 25, 139

PalkaJ. 13

Partridge, J.C. 335

Pitzer,M.R. 152

Popper, A.N. 187,213

Puzdrowski, R.L. 358

Roselinsky, H. 284

Rosen, G. 129

Roth,G. 50,61,94

Schlosser.G. 61,94

Sherwood, N. 129

Staaden, MJ. van 167

Tran,N.B. 284

Wake,D.B. 50

Webb,J.F. 139

Wirtshafter, D. 152 
(c) 1997 S. Karger AG, Basel 
